
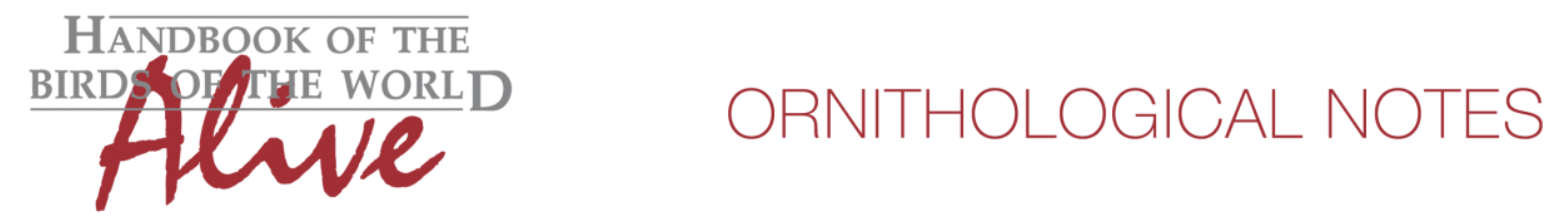

\title{
Notes on the vocalizations of Brown-capped Vireo (Vireo leucophrys) and Warbling Vireo (Vireo gilvus)
}

Peter Boesman

In the following we briefly analyze and compare voice of the different races of Brown-capped Vireo (Vireo leucophrys) and Warbling Vireo (Vireo gilvus). We also try to quantify the extent of any vocal differences using the criteria proposed by Tobias et al. (2010), as a support for taxonomic review. We have made use of sound recordings available on-line from Xeno Canto $(X C)$.

Voice of Warbling Vireo was discussed by Andrew Spencer (http://earbirding.com/blog/archives/3667), leading to the following description of vocal differences:

Eastern Warbling Vireos: song is a pleasant caroling song that rolls along, often ending in an emphatic higher note. The song phrases are typically around 2.5 to 3.5 s long, and are made up of a series rich whistles that are slightly modulated. In the song of eastern Warbling Vireo, most of the initial notes are near the same pitch, with a few higher notes thrown in towards the end of the song.

Western Warbling Vireo songs differ from that of eastern mostly in terms of pitch. Most western songs tend to have more high pitched notes, and these are placed more evenly throughout the song, breaking up the rhythm. While the song of eastern gives the impression of a series of low, caroling notes, the song of western gives a jumbled and less structured feel, with an overall higher pitch.

This can be illustrated by the following two sonograms of typical song:

Eastern stereotype:

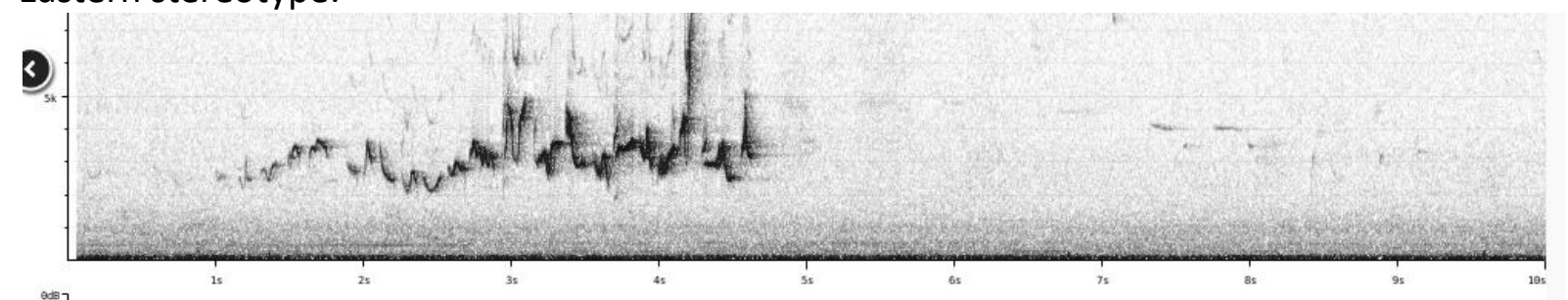

Western stereotype:

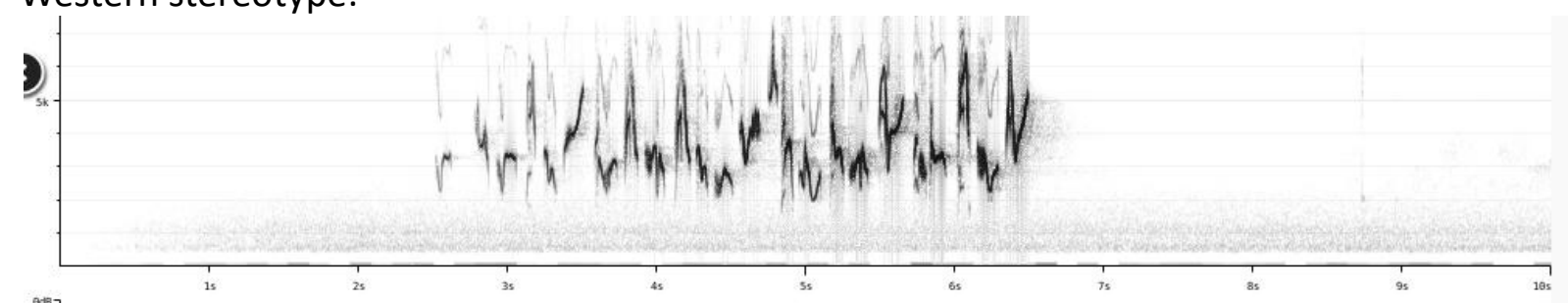

One could quantify this difference by e.g. counting the notes that reach at least $5000 \mathrm{~Hz}$ in the first half and in the second half of the song phrase, and calculate the ratio. Ratio of eastern definitely smaller than 1 , ratio Western about 1 . When applying Tobias criteria, this would normally lead to a score of about 2 (as parameter ranges do overlap slightly). 


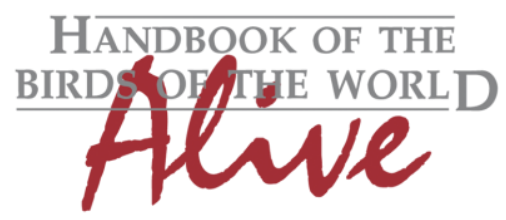

\section{ORNITHOLOGICAL NOTES}

The Neotropical Brown-capped Vireo has a song similar to Warbling Vireo, and they are not always safely told apart, but the main call is very different (the former has high-pitched overslurred buzzy notes, the latter drawn-out low-pitched grating scolds)(Unfortunately, there are apparently no recordings of call of northern races of Brown-capped Vireo, to check if these are the same as southern populations).

Similar to the song comparison of Warbling Vireo, we can also analyze for Brown-capped Vireo whether there are consistent vocal differences between the races of this species.

We haven't found any clear pattern however which would distinguish songs of any formed vocal groups. Northern populations seem to have more often lower-pitched notes (reaching $2 \mathrm{kHz}$ ) than southern birds, but there is considerable overlap.

A few examples:
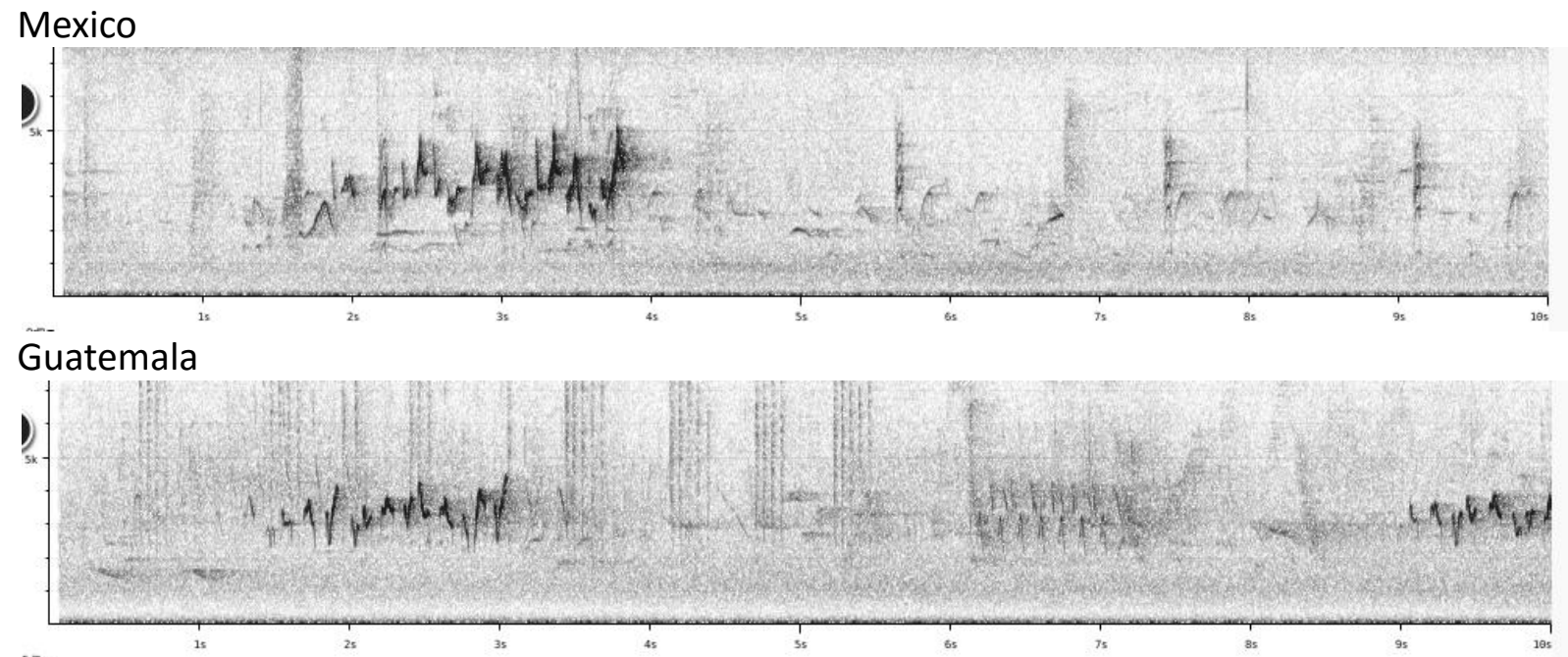

Panama

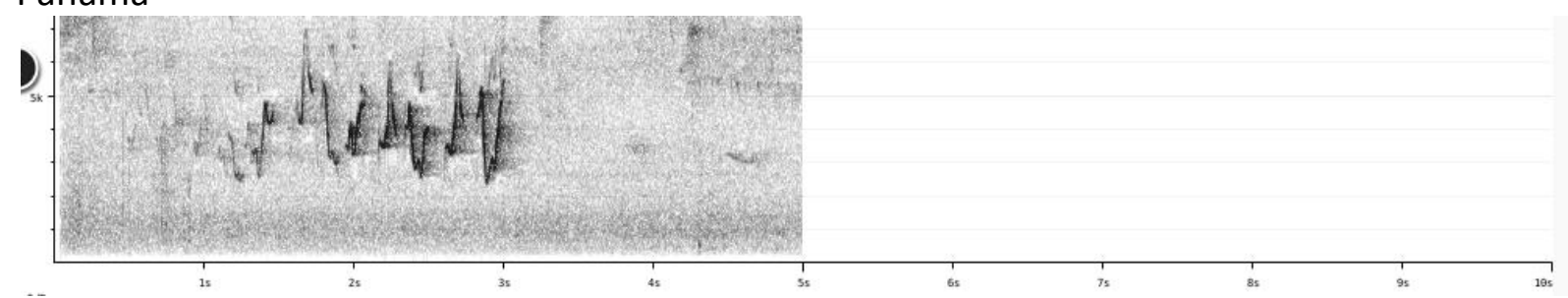

Colombia

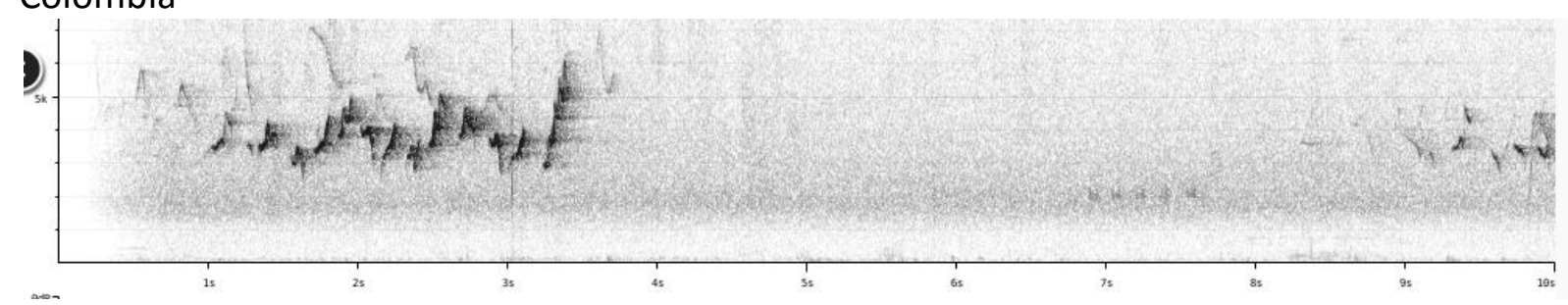

Ecuador

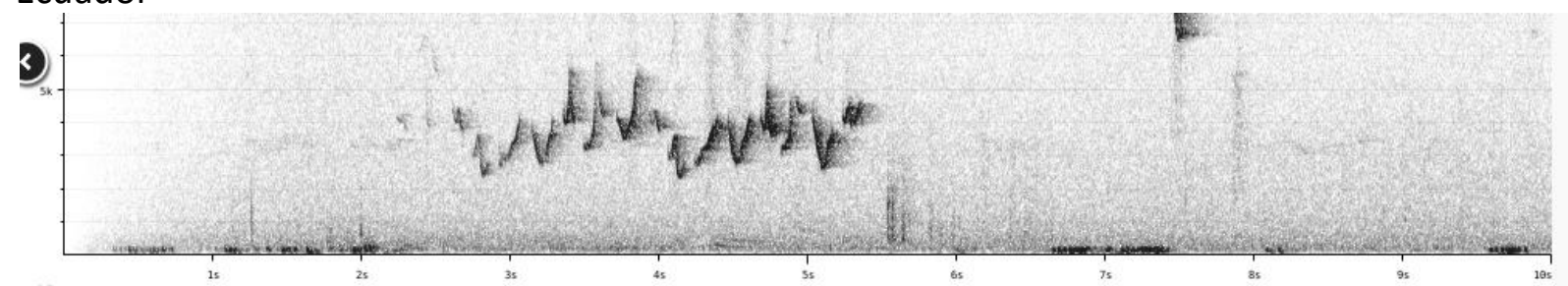



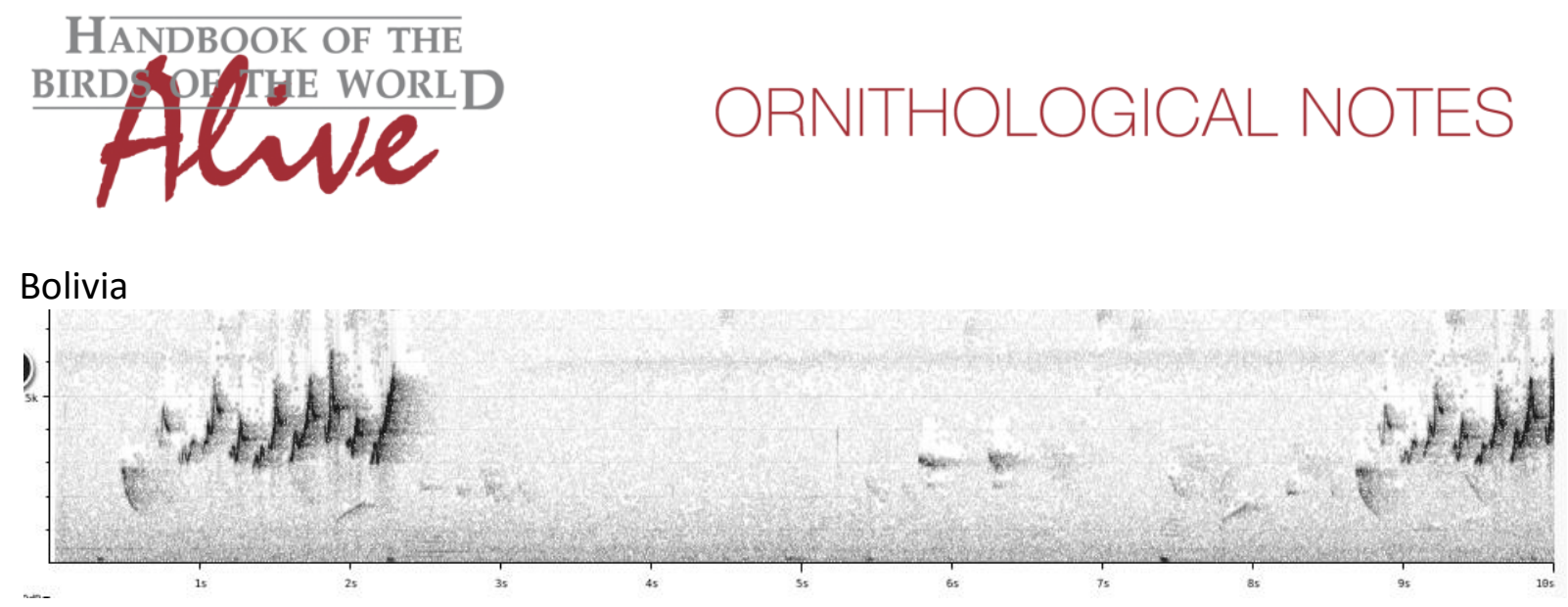

With more precise measurements of the full range of basic sound parameters, one would probably be able to find some differences in averages, but likely with considerable overlap in data ranges. IN such case, when applying Tobias criteria, vocal scores would remain low. At present there are thus no clear indications of any significant vocal difference in song.

As a matter of fact, the very typical main call may possibly be a better indicator for a taxonomic grouping: the high-pitched emphatic buzzy call notes have been recorded as far north as Chriqui, Panama, but not further towards Mexico. Could it be that Northern races (the "amauronotus group") lack this call type?

Example of this typical call from Venezuela:

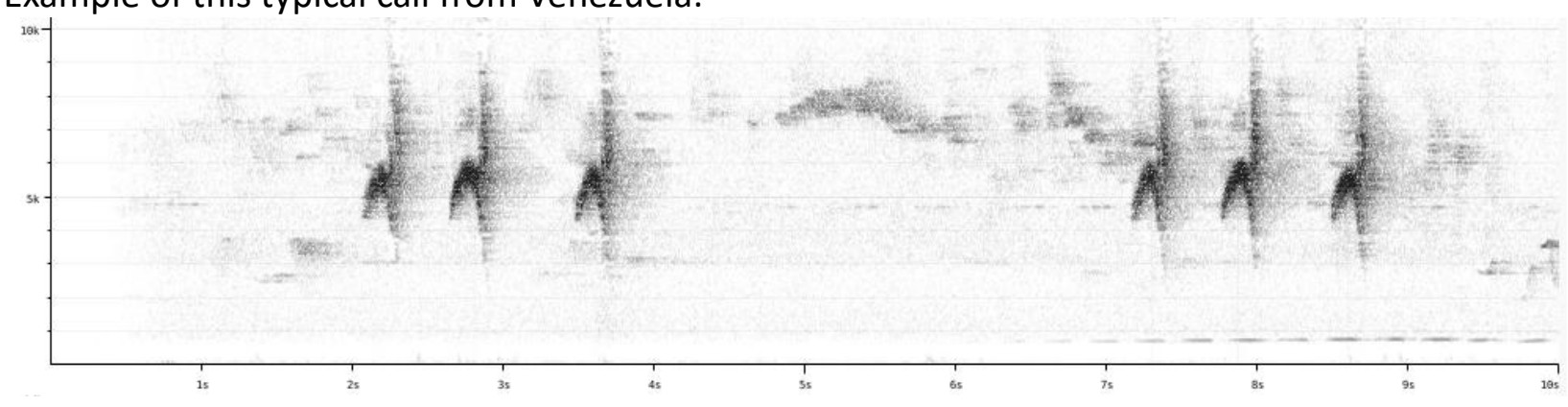

This note was finalized on 21st October 2015, using sound recordings available on-line at that moment. We would like to thank in particular the many sound recordists who placed their recordings for this species on XC.

\section{References}

Tobias, J.A., Seddon, N., Spottiswoode, C.N., Pilgrim, J.D., Fishpool, L.D.C. \& Collar, N.J. (2010). Quantitative criteria for species delimitation. Ibis 152(4): 724-746.

\section{Recommended citation}

Boesman, P. (2016). Notes on the vocalizations of Brown-capped Vireo (Vireo leucophrys) and Warbling Vireo (Vireo gilvus). HBW Alive Ornithological Note 171. In: Handbook of the Birds of the World Alive. Lynx Edicions, Barcelona. (retrieved from http://www.hbw.com/node/932101 on 19 August 2016). 